\title{
Potential Parameters in Assessment of Testicular Toxicity
}

\author{
Gupta PC* and Verma $\mathbf{A}^{\mathbf{1}}$ \\ Department of Zoology, Kashi Naresh Government Post Graduate College, Mahatma Gandhi Kashi Vidyapith, Varanasi-221 002, Bhadohi-221 304, India
}

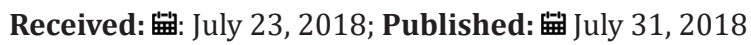

*Corresponding author: Prakash Chandra Gupta, Reproductive Biology and Endocrinology Laboratory, Department of Zoology, Kashi Naresh Government Post Graduate College, Gyanpur, Bhadohi (UP), 221 304- India

Anju Verma, Department of Zoology, Kashi Naresh Government Post Graduate College, Gyanpur, Bhadohi (UP), 221 304- India

\begin{abstract}
Testicular toxicity accounts for about 50\% of infertility cases in men. Though, there are several approaches to detect the toxicity, the histopathological study of alterations occurred in the seminiferous tubules appear to be the most accepted, sensitive and direct marker of testicular toxicity. However, an appropriate understanding of the process of spermatogenesis and its hormonal regulation is necessary to employ the histopathological techniques for the evaluation of testicular toxicity. Further, for most accurate evaluation of testicular toxicity, other key reproductive endpoints must also be considered to know the underlying cause and nature of suppression of spermatogenesis. The present article reviews the conventional histopathological and recent biochemical and molecular techniques available as biomarkers to assess the testicular toxicity.
\end{abstract}

Keywords: Histopathological; Testis; Spermatogenesis; Aromatase; Sertoli cells

Abbreviations: BTB: Blood-Testis Barrier; T: Testosterone; LH: Luteinizing Hormone; FSH: Follicle-Stimulating Hormone; GnRH: Gonadotropins Releasing Hormones; ABP: Androgen-Binding Protein; DHT: Dihydrotestosterone; E2: Estradiol; PRL: Prolactin; LDH: Lactate Dehydrogenase; OS: Oxidative Stress; ROS: Reactive Oxygen Species; LPO: Lipid Peroxidation; StAR: Steroidogenic Acute Regulatory; SCC: Side Chain Cleavage; PCNA: Proliferating Cell Nuclear Antigen; TUNEL: Terminal Deoxynucleotidyl Transferase dUTP Nick End Labeling; SOD: Superoxide Dismutase; CAT: Catalase; HSD: Hydroxysteroid Dehydrogenase;

\section{Introduction}

Testicular toxicity accounts for about $50 \%$ of infertility cases in men [1]. The critical factors responsible for testicular toxicity include hormonal, environmental, behavioral and nutritional imbalances [2]. Therapeutic drugs can often adversely affect male fertility by injuring testicular germ cells or disturbing hormonal levels leading to decreased semen quality. Though, there are several approaches to detect the toxicity, the histopathological study of alterations occurred in the seminiferous tubules appear to be the most accepted, sensitive and direct marker of toxicity. However, this conventional approach includes certain quantitative analyses which are tedious, and in absence expertise, may produce defective figures. Therefore, there is an urgent need to explore quick and efficient techniques to detect and explain the cause and nature of testicular toxicity. The present article tries to critically review the conventional histopathological and recent biochemical and molecular techniques as biomarkers to assess the testicular toxicity.

\section{Spermatogenesis and Hormonal Regulation}

Before we discuss the techniques available for the detection of testicular toxicity, it is essential to understand the basics of spermatogenesis and its hormonal regulation in testis. Testis performs two highly organized and tightly controlled events, called spermatogenesis and steroidogenesis respectively. Spermatogenesis in testis is a highly complicated, dynamic and synchronized process of germ cell proliferation and differentiation that occurs in the seminiferous tubules under the structural and nutritive support of somatic Sertoli cells [3]. Sertoli cells are primarily involved in the formation of BTB, secretion of testicular fluid, phagocytosis of abnormal germ cells, and production of a variety of binding proteins (particularly ABP, transferrin, and ceruloplasmin), hormones (inhibin and activin) and many of the growth factors. Leydig cells in the interstitial compartment of the testis are engaged in testosterone production [4]. The spermatogenesis in testis is under the control of hormones secreted from the hypothalamo-hypophysial-gonadal axis. Biosynthesis and secretion of gonadotropins viz. LH and FSH from the anterior pituitary gland are under the control of GnRH from the hypothalamus [5].

FSH acts directly on Sertoli cells to support spermatogenesis in the seminiferous tubules, whereas, LH acts on interstitial Leydig cells to stimulate biosynthesis and release of $\mathrm{T}$. $\mathrm{T}$ produced by Leydig cells diffuses into the interstitial space through the basement 
membrane and into the seminiferous tubules, where it enters Sertoli cells to be converted to with DHT. Both T and DHT, leave Sertoli cells and get accumulated around the dividing germ cells. Both FSH and intratesticular T, synergistically play a crucial role in normal spermatogenesis. The intratesticular level of $\mathrm{T}$ is around 40- to 100- fold higher than the serum level which is an essential requirement to support spermatogenesis in the seminiferous tubules [5]. In addition to T, FSH and LH, there are others namely E2, PRL and THs, and a number of several growth factors which are locally produced by different cells in the testis and play a crucial role in the regulation of the spermatogenesis.

\section{Histopathological Techniques}

Histopathological examination of testis involves both qualitative as well as quantitative procedures. For qualitative analyses, affected seminiferous tubules in testis are grouped into degenerating and atrophic ones depending upon the severity of the alterations. The most common histological alterations observed initially under testicular toxicity involve loosening of germinal epithelium, exfoliation of germ cells, intraepithelial vacuolation, formation of multinucleated giant cells, occurrence of uninucleated giant round spermatids, presence of spermatids at different stages (particularly in stages IX, X, and XI) of spermatogenic cycle in the same tubule, failure of spermiation, phagocytosis of abnormal sperm by Sertoli cell, focal damage to germinal epithelium, and marginal condensation of chromatin material in the round spermatids. Atrophic tubules, on the other hand, show an ill-defined germinal epithelium of very low height (formed due to large-scale sloughing of germ cells) containing Sertoli cells with or without a few germ cells [6-8]. Quantitative alterations in testicular toxicity are evaluated by enumeration of germ cell number in stage VII tubules $[6,9]$, measurement of the diameter of the seminiferous tubules and the height of the germinal epithelium in stage VII round or slightly oblique tubules. To determine the alterations in the kinetics of spermatogenesis, the seminiferous tubules are identified and counted with respect to the stages of spermatogenesis (grouped as I-IV, V-VI, VII-VIII, IX-X, XI-XII and unidentifiable) [6].

\section{Tissue Biochemistry}

\section{Levels of Glucose and D-Lactate in Testis}

Amrolia et al., (1998) reported that in addition to LH, glucose is also essential for androgen biosynthesis in Leydig cells. Therefore, determination of glucose level in the testis may prove an explanation for a decline in testosterone biosynthesis. Sertoli cells take up glucose from the extracellular matrix through specific glucose transporters (GLUT1 and GLUT3) and convert it into D-lactate [11]. It is established that lactate is essential for the development and survival of germ cells [12]. Therefore, determination of levels of glucose and D-lactate in the testis may prove an explanation for a decreased $\mathrm{T}$ biosynthesis and an increased germ cell apoptosis in the testis.

\section{Determination of Lactate Dehydrogenase Activity}

LDH in Sertoli cells catalyzes the conversion of pyruvate to D-lactate which exerts an anti-apoptotic effect as stated above [12]. Therefore, measuring the LDH activity is a good parameter to explain lactate production in testis.

\section{Determination of Steroidogenic Activity in Testis}

The testicular steroidogenic enzymes, $3 \beta$ hydroxysteroid dehydrogenase $3 \beta-$ HSD and $17 \beta-$ HSD are key biomarkers to assess any alteration in testosterone biosynthesis by Leydig cells. Reduction in the activities of the above enzymes results in a diminished level of $\mathrm{T}$ in the testis as well as in the serum [13].

\section{Determination of $\mathrm{OS}$ in Testis}

OS is the chief cause of testicular toxicity and male infertility. There are so many factors (cryptorchidism, testicular torsion, varicocele, hyperthyroidism, infection, physical exertion, hormonal imbalance, the impact of xenobiotics) that induce the formation of ROS in the testis [14]. ROS is one of the key causes germ cell of apoptosis [15] and alteration in glucose homeostasis in testis, especially in terms of lactate production and modulation of LDH activity [16]. The severity of OS is determined by estimating the level of LPO and activities of antioxidant enzymes, superoxide SOD and CAT in the testis.

\section{Hormone Assays}

\section{Levels of $\mathrm{T}$ and $\mathrm{E} 2$}

As stated above, a high intratesticular level of $\mathrm{T}$ is essential for the survival and successful progression of spermatogenesis. Further, structural and functional activities of accessory sex organs, as well as secondary sexual characteristics including libido, are largely dependent on $\mathrm{T}$ level in blood. Therefore, measurement of intratesticular and serum $\mathrm{T}$ levels is an efficient tool to determine the steroidogenic activity in testis and secretory activities in the sex organs respectively. Recently, results from the experiments conducted in vivo and in vitro demonstrated that estrogens play an important role in spermatogenesis (proliferation, apoptosis, survival, and maturation) in vertebrates. At least, it is supported by the presence of estrogen receptors, ER $\alpha$ and/or ER $\beta$, in different testicular cells and the simultaneous expression of aromatase in all germ cells (especially in meiotic and post-meiotic stages) [17]. An excess of E2 in testis induces germ cell apoptosis due to downregulation of gonadotropins and steroidogenic enzymes, leading to impaired spermatogenesis [18]. Thus, it becomes crucial to consider the intratesticular level of E2 to find out the hormonal imbalance.

\section{Serum Levels of LH, FSH, PRL, and THs}

FSH receptor is expressed in the Sertoli cells, whereas LH receptor is expressed in the interstitial Leydig cells, suggesting that FSH (directly) and LH (indirectly) exert their actions on spermatogenesis mainly through the regulation of Sertoli cell factors. Studies in rodents show that FSH increases germ cell population by several folds by increasing the complement of spermatogonia and spermatocytes, but it was unable to generate spermatids in the absence of T [19]. LH and PRL, in addition to T, are predominant factors that control the expression and activity of steroidogenic enzymes in adult Leydig cells [20]. LH is responsible for $\mathrm{T}$ biosynthesis in the testis, and is under the feedback inhibition by T [21]. PRL, a $23 \mathrm{kDa}$ hormone, has been associated primarily 
with male infertility, although, its role in male reproduction has been poorly established. PRL is known to play a role in T biosynthesis through upregulation of LH receptors on Leydig cells [22]. Acute hyperprolactinemia is known to suppress $\mathrm{T}$ biosynthesis and male fertility through PRL induced hypersecretion of adrenal corticoids or by inhibiting the secretion of GnRH through PRL receptors on hypothalamic dopaminergic neurons [23]. On the other hand, altered levels of THs are considered to evoke OS in various tissues including testis [24]. Therefore, serum levels of LH, FSH, PRL, and THs should be measured to assess their roles in testicular toxicity.

\section{Immunoblot Analyses of Testicular Proteins}

\section{StAR and P450scc Proteins}

The steroidogenic acute regulatory protein (Star), primarily present in all steroid-producing cells including Leydig cells, is a transport protein that regulates the transport of cholesterol in the mitochondria, a rate limiting step in the production of steroid hormones. Cholesterol side-chain cleavage enzyme (P450scc) is another mitochondrial enzyme that catalyzes the conversion of cholesterol to pregnenolone. This is the first reaction in the process of steroidogenesis in all mammalian tissues [25]. Thus, the above two proteins are crucial in $\mathrm{T}$ biosynthesis and need to be studied in the testicular toxicity.

\section{Expression of Aromatase Enzyme}

The cytochrome P450 aromatase converts irreversibly androgens into estrogens and is present in various cells of mammalian testes. In rodents, it is expressed in all testicular cells except peritubular cells [17]. The presence of aromatase in the Leydig cells of primates and humans is well established.

\section{Expressions of Androgen Receptor (AR) and Estrogen Receptor (ER)}

T signaling through AR is essential for normal spermatogenesis and this is mediated by Sertoli and peri-tubular myoid (PTM) cells, since AR is not expressed in the developing germ cell lineage [22]. Further, estrogen receptors, ER $\alpha$ and/or ER $\beta$, are also reported to be present in a variety of testicular cells to mediate the effects of estrogens [17]. The expression of the above receptor must be considered in the assessment of testicular toxicity.

\section{Caspase-3 and PCNA Proteins}

Caspase-3 is an important endpoint marker protein for determination of apoptotic index in testis. The expression of caspase-3 protein is increased under the testicular toxicity. PCNA (Proliferating cell nuclear antigen), a $36 \mathrm{kDa}$ protein, on the other hand, is a reliable biomarker of germ cell proliferation. It is high during all phases of the cell cycle (most abundance in late G1 and $\mathrm{S}$ phase), and the expression is decreased prominently under impaired germ cell proliferation [27].

\section{TUNEL Analysis for Apoptosis}

Identification and counting the apoptotic germ cells at early stages in seminiferous tubules has always being a tough task for researchers. However, TUNEL (Terminal deoxynucleotidyl transferase dUTP nick end labeling) is a sensitive biomarker to enumerate the accurate number and types of germ cells undergoing apoptosis to detect the severity of the testicular toxicity [28].

\section{Conclusion}

Testicular toxicity testing has always been a challenging issue due to the lack of simple and robust screening methods. The search for reliable biomarkers for evaluation of testicular toxicity will turn predictions more feasible, with decreased time and resources.

\section{References}

1. World Health Organization (2017) WHO manual for the standardized investigation and diagnosis of the infertile couple.

2. Sharpe RM, Franks S (2002) Environment, lifestyle and infertility-an intergenerational issue. Nat Cell Biol 4: 33-40.

3. Hess RA, Renato de Franca L (2008) Spermatogenesis and cycle of the seminiferous epithelium. Adv Exp Med Biol 636: 1-15.

4. Ge R, Chen G, Hardy MP (2008) The role of the Leydig cell in spermatogenic function. Adv Exp Med Biol 636: 255-269.

5. Coviello AD, Matsumoto AM, Bremner WJ, Herbst KL, Amory JK, et al. (2005) Low-Dose Human Chorionic Gonadotropin Maintains Intratesticular Testosterone in Normal Men with Testosterone-Induced Gonadotropin Suppression. The J Clin Endocrinol \& Metabol Journal of Clinical Endocrinology \& Metabolism 90(5): 2595-2602.

6. Russell LD, Ettlin RA, Hikim APS, Clegg ED (1990) Histological and Histopathological Evaluation of the Testis. Cache River Press, Clearwater 16(1): 83.

7. Gupta PC (2012) A preliminary study on effects of leaf extract of Ficus bengalensis (Linn.) on spermatogenesis and fertility in albino mice. Int J Pharm Tech Research 4(1): 226-232.

8. Gupta PC (2015) Study on anti-spermatogenic and antifertility effects of Terminalia chebula in albino mice. Journal of Biology and Nature 3(4): 121-131.

9. Abercrombie M (1946) Estimation of nuclear population from microtome sections. Anat Rec 94: 239-247.

10. Amrolia P, Sullivan MHF, Garside D, Baldwin SA, Cooke BA (1988) An investigation of glucose uptake in relation to steroidogenesis in rat testis and tumor Leydig cells. Biochem J 249: 925-928.

11. Alves MG, Martins AD, Cavaco JE, Socorro S, Oliveira PF (2013) Diabetes, insulin mediated glucose metabolism and Sertoli/blood-testis barrier function. Tissue Barriers 1(2): 23992-24102.

12. Erkkila K, Aito H, Aalto K, Pentikainen V, Dunkel L (2002) Lactate inhibits germ cell apoptosis in the human testis. Mol Hum Reprod 8(2): 109-117.

13. Stocco D, McPhaul M (2006) Physiology of testicular steroidogenesis. In Knobil and Neill's Physiology of Reproduction. Neill JD, ed. St Louis, MO: Elsevier Academic Press pp. 977-1016.

14. Aitken RJ, Roman SD (2008) Antioxidant systems and oxidative stress in the testes. Oxidative Medicines and Cellular Longevity 1(1): 15-24.

15. Rao AV, Shaha C (2000) Role of glutathione S-transferases in oxidative stress-induced male germ cell apoptosis. Free Radical Biol Med 29(10): 1015-1027.

16. Rossi SP, Windschuttl S, Matzkin ME, Rey Ares V, Terradas C, et al. (2016) Reactive oxygen species (ROS) production triggered by prostaglandin D2 (PGD2) regulates lactate dehydrogenase (LDH) expression/activity in TM4 Sertoli cells. Mol Cell Endocrinol 434: 154-165.

17. Carreau S, Bouraima Lelong H, Delalande C (2012) Role of estrogens in spermatogenesis. Front Biosci 1(4): 1-11.

18. Blanco Rodriguez J, Martinez Garcia C (1996) Induction of apoptotic cell 
death in the seminiferous tubule of the adult rat testis: assessment of the germ cell types that exhibit the ability to enter apoptosis after hormone suppression by oestradiol treatment. Int J Androl 19(4): 237-247.

19. Russell LD, Kershaw M, Borg KE, El Shennawy A, Rulli SS, et al. (1998) Hormonal regulation of spermatogenesis in the hypophysectomized rat: FSH maintenance of cellular viability during pubertal spermatogenesis. J Androl 19(3): 308-319; discussion 341-342.

20. Payne AH, Hales DB (2004) Overview of steroidogenic enzymes in the pathway from cholesterol to active steroid hormones. Endocrine Rev 25(6): 947-970.

21. Juneja HS, Motta M, Massa R, Zanisi M, Martini L (1973) Feedback control of gonadotropin secretion in the male. In Sperm Action. Hubunont PO, Hermite ML, Schwers J, eds. Progress in Reproductive Biology, Karger, Basel, Switzerland pp. 162-173.

22. Mathur U, Bartke A, Weisz J (1975) Effects of Prolactin and LH on the activity of $\Delta 5-3 \beta$ hydroxy-steroid dehydrogenase, dihydro orotic dehydrogenase, $\beta$-hydroxybutyrate dehydrogenase and glucose 6 phosphate dehydrogenase in the testis of the dwarf mice. Indian J Physiol Pharmacol 19(2): 58-64.

\section{ISSN: 2574-1241}

DOI: 10.26717/BJSTR.2018.07.001504

Prakash Chandra Gupta. Biomed J Sci \& Tech Res

(C) This work is licensed under Creative

Submission Link: https://biomedres.us/submit-manuscript.php
23. Bartke A (1986) Hyperprolactinemia and male reproduction. In Andrology, Male Fertility and Sterility. Paulsen JD, NegroInternational Vilar A, Lucina E, Martini L, eds. New York, NY, USA: Academic Press pp. 101-123.

24. Das K, Chainy GB (2004) Thyroid hormone influences antioxidant defense system in adult rat brain. Neurochem Res 29(9): 1755-1766.

25. Hanukoglu I (1992) Steroidogenic enzymes: structure, function, and role in regulation of steroid hormone biosynthesis. J Steroid Biochem Mol Biol 43 (8): 779-804.

26. Ohara L, Smith LB (2015) Androgen receptor roles in spermatogenesis and infertility. Best Pract \& Res Clin Endocrinol \& Metabol. 29(4): 595605.

27. Hall PA, Levison DA, Woods AL, Yu CCW, Kellock DB, et al. (1990) Proliferating cell nuclear antigen (PCNA) immunolocalization in paraffin sections: an index of cell proliferation with evidence of deregulated expression in some neoplasms. J Pathol 162(4): 285-294.

28. Kyrylkova K, Kyryachenko S, Leid M, Kioussi C (2012) Detection of apoptosis by TUNEL assay. Methods Mol Bio 887: 41-47.

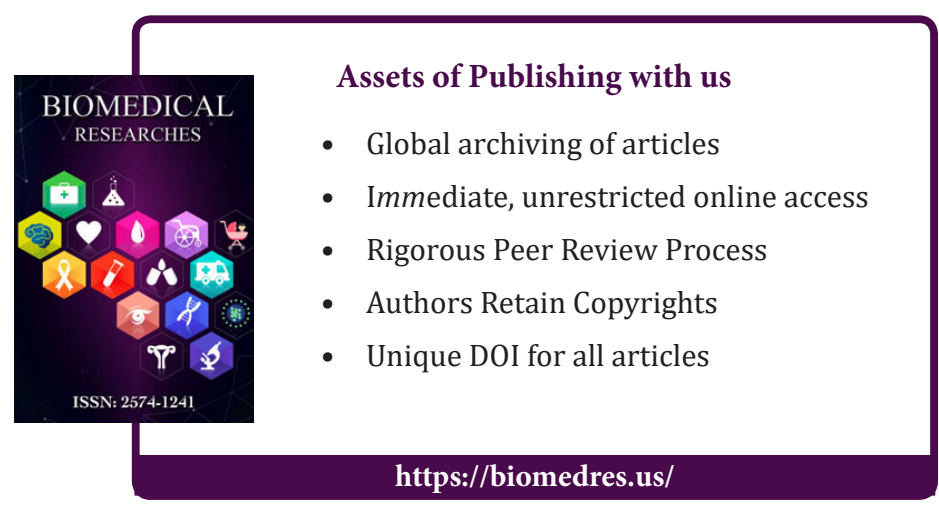

